\title{
Predicting the future of forests in the Mediterranean under climate change, with niche- and process-based models: $\mathrm{CO}_{2}$ matters!
}

\author{
TREVOR KEENAN*†, JOSEP MARIA SERRA $\ddagger$ FRANCISCO LLORET*\$, \\ MIQUEL NINYEROLA $\ddagger$ and SANTIAGO SABATE* \\ *Center of Ecological Research and Forestry Applications (CREAF), Autonomous University of Barcelona (UAB), 08193, Barcelona, \\ Spain, $\dagger$ Richardson Laboratory, Department of Organismic and Evolutionary Biology, Harvard University, 02138 Cambridge, MA, \\ USA, $\ddagger$ Botany Unit, Department of Animal Biology, Plant Biology and Ecology, Autonomous University of Barcelona (UAB), \\ 08193 Barcelona, Spain, §Ecology Unit, Department of Animal Biology, Plant Biology and Ecology, Autonomous University of \\ Barcelona (UAB), 08193 Barcelona, Spain, Department of Ecology, University of Barcelona (UB), 08007 Barcelona, Spain
}

\begin{abstract}
Assessing the potential future of current forest stands is a key to design conservation strategies and understanding potential future impacts to ecosystem service supplies. This is particularly true in the Mediterranean basin, where important future climatic changes are expected. Here, we assess and compare two commonly used modeling approaches (niche- and process-based models) to project the future of current stands of three forest species with contrasting distributions, using regionalized climate for continental Spain. Results highlight variability in model ability to estimate current distributions, and the inherent large uncertainty involved in making projections into the future. $\mathrm{CO}_{2}$ fertilization through projected increased atmospheric $\mathrm{CO}_{2}$ concentrations is shown to increase forest productivity in the mechanistic process-based model (despite increased drought stress) by up to three times that of the non- $\mathrm{CO}_{2}$ fertilization scenario by the period 2050-2080, which is in stark contrast to projections of reduced habitat suitability from the niche-based models by the same period. This highlights the importance of introducing aspects of plant biogeochemistry into current niche-based models for a realistic projection of future species distributions. We conclude that the future of current Mediterranean forest stands is highly uncertain and suggest that a new synergy between niche- and process-based models is urgently needed in order to improve our predictive ability.
\end{abstract}

Keywords: BIOMOD, $\mathrm{CO}_{2}$ fertilization, drought, GOTILWA + , niche-based models, Pinus halepensis, Pinus sylvestris, Quercus ilex, species distribution

Received 19 January 2010; revised version received 27 April 2010 and accepted 6 May 2010

\section{Introduction}

Detailed knowledge of species' ecological and geographic distributions is fundamental for conservation planning and forecasting (Ferrier, 2002; Funk \& Richardson, 2002; Rushton et al., 2004), for understanding ecological and evolutionary determinants of the spatial patterns of biodiversity (Ricklefs, 2004), and the potential response of these distributions to future climatic change (e.g. Thomas et al., 2004; Araújo et al., 2005a, b; Thuiller et al., 2005). This is of particular importance in the Mediterranean region, which has a high diversity of environments and harbors Europe's greatest diversity of vegetation and fauna (Cowling

Correspondence: T. Keenan, Center of Ecological Research and Forestry Applications (CREAF), Autonomous University of Barcelona (UAB), 08193, Barcelona, Spain, tel. + 1617496 0825, e-mail: tkeenan@oeb.harvard.edu et al., 1996). This region is not only a biodiversity hotspot (Underwood et al., 2009), it has also been identified as a climatic change hotspot (Giorgi, 2006) because (1) climate projections consistently project significant increases in temperature, and decreases in precipitation in the Mediterranean basin (Gibelin \& Deque, 2003; Giorgi et al., 2004) and (2) such potential change may have a large effect on current Mediterranean forests and the related ecosystem service supply (Schröter $e t$ al., 2005).

Models are the most feasible and efficient way to assess spatial biodiversity and responses to climatic drivers over large spatial and temporal scales (Thuiller, 2007). Species-specific models fall broadly into two categories: empirical niche-based or habitat models and process-based models (see Kearney, 2006). These contrasting methodologies, however, often give conflicting results (Thuiller et al., 2008).

Also known as ecological species distribution models, bioclimatic envelopes, or habitat models, niche-based 
models are by far the most commonly used method for predicting species geo-climatic distributions. Such models typically use a variety of correlative methods to provide detailed predictions of distributions by relating presence or abundance of species to gradients of observed environmental predictors. As such, nichebased models are used extensively and have provided researchers with an innovative tool to explore diverse questions in ecology and conservation (see Peterson, 2007). In particular, it has become common to use such models to assess potential distribution responses to future climate scenarios (e.g., Bakkenes et al., 2002; Araújo et al., 2004; Skov \& Svenning, 2004; Thomas et al., 2004; Thuiller et al., 2005; Gomez-Mendoza \& Arriaga, 2007; Thuiller, 2010), using sophisticated interpolation of climate data (e.g., Hijmans et al., 2005). One of the main advantages of niche-based models is their relative simplicity, making it straightforward to develop species-specific models, which make use of the large data sets available (e.g., Forest inventories, regionalized climate).

For terrestrial vegetation, the term 'process-based model' incorporates a broad range of methodologies for describing eco-physiological processes, from purely empirical relationships to mechanistic descriptions based on physical laws. Various types of process-based models are used and under development, such as gap models (Pacala et al., 1993; Bugmann, 2001), landscape models (Lischke et al., 2006; Scheller \& Mladenoff, 2007), fitness-based models (Chuine \& Beaubien, 2001), or sophisticated 'hybrid' dynamic vegetation models (e.g., Sitch et al., 2008), which focus on achieving a balance between realism, accuracy and complexity. The suite of available models represents a range from very detailed species-specific models which describe stand structure and hourly plant physiological processes (i.e. coupled photosynthesis, respiration, and water balance), to general models based on fitness probability matrices. A process-based model can potentially allow for the highlighting of processes involved in range shifts or extinction. To date, various processbased approaches have been developed for predicting species distributions (see Jeltsch et al., 2008 for a review). These have been explicitly empirical, and link simple indexes of survival and reproduction with impacts of frost, drought, and windthrow to produce a presence-absence indicator. The use of these empirical models to make predictions of species range shifts is rare for species ranges at the regional scale (Hijmans \& Graham, 2006; Jeltsch et al., 2008).

Many mechanistic process-based model studies, supported by experimental campaigns such as the FACE project (Ainsworth \& Long, 2005; Ainsworth \& Rogers, 2007), as well as growth and yield surveys, suggest that global warming will have a positive impact on forest productivity (van der Meer et al., 2002; Nigh et al., 2004; Norby \& Luo, 2004; Briceño-Elizondo et al., 2006; Gaucharel et al., 2008), due to the direct fertilization effect of increased $\mathrm{CO}_{2}$ and indirect effects such as lengthening of the growing period [but see contrary examples such as Zierl \& Bugmann (2007)]. Results vary among experimental systems, especially when considering potential acclimation (Körner, 2006) and nutrient limitation (Zaehle et al., 2010), and remain the focus of much study. On the other hand, results from statistical niche-based models are supported by a growing body of ecological literature that suggests that the narrow climatic adaptation of many tree species may lead to many populations being poorly suited to their environment, resulting in large alteration to potential distributions towards the end of the 21st Century (Davis \& Shaw, 2001; Iverson \& Prasad, 2001; Thomas et al., 2004; St Clair \& Howe, 2007; Benito-Garzon et al., 2008). Within studies, different modeling methods yield highly divergent predictions, even when spatial assessments of model accuracy appear excellent (Araújo et al., 2005a, b; Kharouba et al., 2009).

It is of great importance to develop several methods independently and to compare (for the same species and under the same scenarios) their predictions in order to identify both robust results and model inadequacies (Beaumont et al., 2007). Such cross comparisons may provide information on which policy makers and stakeholders can rely. Yet, despite the uncertainty generated by contrasting experimental results, the variety of modeling approaches available (Jeltsch et al., 2008), and studies that have highlighted differences between niche-based modeling approaches (Elith et al., 2006; Hijmans \& Graham, 2006), niche-based model predictions are rarely compared against other modeling approaches. Of particular relevance to this study, the models used in previous comparisons (e.g., Hijmans \& Graham, 2006; Jeltsch et al., 2008; Coops et al., 2009; Morin \& Thuiller, 2009) have not described the indirect effect of $\mathrm{CO}_{2}$ driven forest productivity on the suitability of a site (but see Rickebusch et al., 2008).

This paper has three purposes. First, we consider the effectiveness of an empirically derived multi-nichebased model ensemble, applying the BIOMOD-R package (Thuiller et al., 2009) with regionalized present-day (1950-1998) climate, to predict the distributions of three forest species in continental Spain. These species are presently distributed along a gradient from drier (Pinus halepensis), to mesic (Quercus ilex) and moister conditions (P. sylvestris). Second, we assess potential future climate driven changes in current forest stands using both the niche-based approach and a mechanistic process-based forest growth model (GOTILWA +). Third, 
we use the process-based simulations of projected future forest productivity (with and without $\mathrm{CO}_{2}$ fertilization) to identify possible processes responsible for the large differences observed in future projections from the two modeling approaches. We then suggest possible means by which to improve future model efforts.

\section{Materials and methods}

\section{Selected region and study species}

We focused on the region of continental Spain, which contains a large altitudinal gradient (sea level to $3500 \mathrm{~m}$ ) and a mosaic of different climates (from semiarid climates to Mediterranean and humid Atlantic climates). The Third Spanish National Forest Inventory (Ministerio de Agricultura PyA, 2007) surveyed the forested surface of the Spanish Iberian Peninsula $\left(492173 \mathrm{~km}^{2}\right)$ with an approximate density of 1 plot $\mathrm{km}^{2}$. Each of the resulting 89365 circular plots was located in the field by giving its Universal Transverse Mercator (UTM 30N) coordinates. We extracted the presence/absence data for three species with distinct topoclimatic distributions: two tree species (Q. ilex, P. halepensis) commonly found in Mediterranean forests of the study region, and one species (P. sylvestris) which is found at the most southern limits of its distribution (Fig. 1).

\section{Climatic data}

From 1900 to 2000, a reconstructed climatic data time series based on the CRU05 (1901-2000) monthly data set (New et al., 1999) was used, with global atmospheric concentrations of $\mathrm{CO}_{2}$ from 1901 to 2000 obtained from the Carbon Cycle Model Linkage Project (McGuire et al., 2001).

We applied the climatic projection for period 2001-2100 generated by the HadCM3 global circulation model using the A1 scenario (IPCC WGI, 2007) as an indicator for the effect of possible future climate change on species distributions and productivity. The HadCM3 model with the A1 scenario uses an estimated increase in atmospheric $\mathrm{CO}_{2}$ to $810 \mathrm{ppm}$ by 2080 , with an associated increase in temperature of $3.1^{\circ} \mathrm{C}$ by 2080 for the area included in this study (in comparison with the average temperatures for the 1960-1990 period), and a slight decrease in precipitation.

The present-day regionalization was created by GIS modeling from ground data (1950-1998; 1068 thermometric and 1999 pluviometric meteorological stations) from the Spanish weather monitoring system (National Weather Institute; http:// www.aemet.es). The regionalization method chosen was multiple regression with residual correction (spatially interpolated using inverse distance weighting in the case of mean temperatures or splines in the case of precipitation). The climate predictors were altitude, latitude, continentality (linear or quadratic distances to Mediterranean, Atlantic and Cantabric coasts) and potential global solar radiation; all of them derived from a DEM (Digital Elevation Model). A holdout crossvalidation, using a fitting set $(60 \%)$ and a testing set $(40 \%)$, was applied to compute the RMSE for the monthly data (between 0.8 and $1.6^{\circ} \mathrm{C}$ in the case of temperature and between 6 and $20 \mathrm{~mm}$ in the case of precipitation). See Ninyerola et al. $(2007 a, b)$ for more details on the methodology used. The resulting maps have a $200 \mathrm{~m}$ spatial resolution, although in this study we have generalized the matrix into a $1 \mathrm{~km}$ grid for computational purposes.

Future regionalized climate was obtained using an approximation based on differences between the past climate (CRU) and the climate projection from the HADCM3 model using the A1 storyline, thus combining the predictive information of the GCM with the topoclimatic data provided by ground stations.

\section{Niche-based models}

We performed the projections using nine different and widely used niche-based modeling techniques, within the BIOMOD computational framework (Thuiller, 2003; Thuiller et al., 2009), as outlined in Table 1.

All models used in this study need information about presences and absences to be able to determine suitable conditions for a given species. Pseudo-absences were randomly selected from stands at least $10 \mathrm{~km}$ distant to a presence where the target species was not recorded in the Forest Inventory. The number of pseudo-absences and presences were equaled in order to keep prevalence constant. A holdout crossvalidation
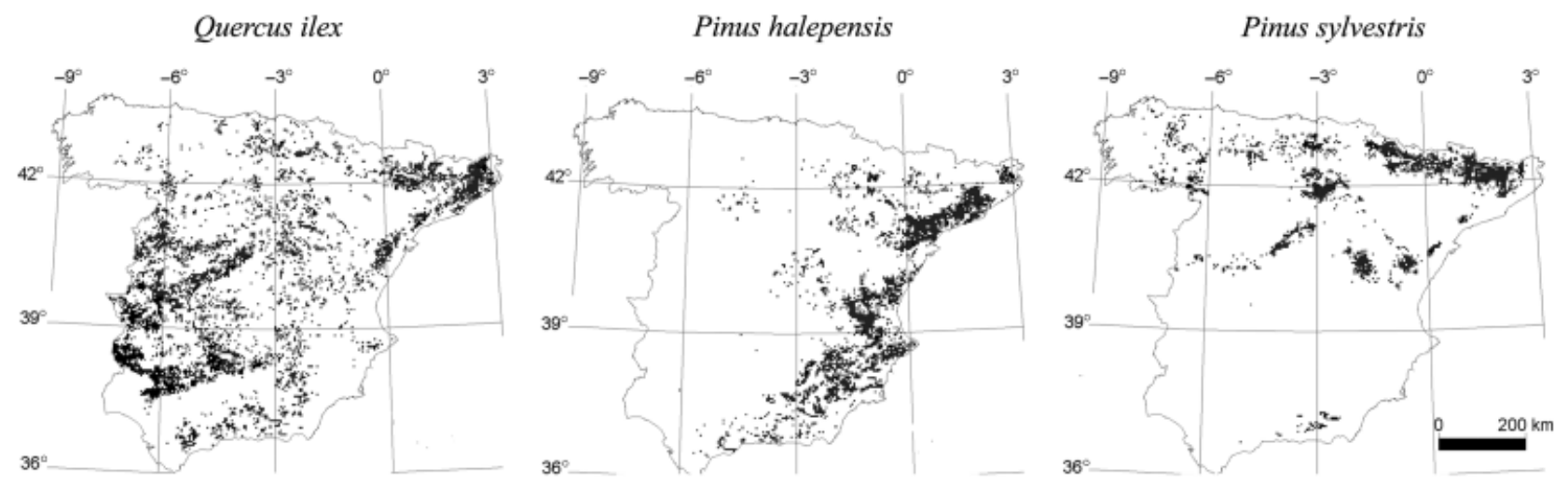

Fig. 1 Distribution of presence records from the Third Spanish National Inventory for (a) Quercus ilex, (b) Pinus halepensis, and (c) P. sylvestris. 
Table 1 Niche-based models used in this study

\begin{tabular}{|c|c|c|c|}
\hline $\begin{array}{l}\text { Model } \\
\text { no. }\end{array}$ & Abbreviation & Method & References \\
\hline 1. & RF (random forest) & $\begin{array}{l}\text { A machine-learning method - a combination of tree } \\
\text { predictors such that each tree depends on the } \\
\text { values of a random vector sampled } \\
\text { independently and with the same distribution for } \\
\text { all trees in the forest. }\end{array}$ & Breiman (2001) \\
\hline 2. & CTA (classification tree analysis) & $\begin{array}{l}\text { A classification method - a 50-fold cross-validation } \\
\text { to select the best trade-off between the number of } \\
\text { leaves of the tree and the explained deviance. }\end{array}$ & Breiman et al. (1984) \\
\hline 3. & $\begin{array}{l}\text { GBM (generalized boosting } \\
\text { model) }\end{array}$ & $\begin{array}{l}\text { A machine-learning method - combines a boosting } \\
\text { algorithm and a regression tree algorithm to } \\
\text { construct an 'ensemble' of trees. }\end{array}$ & Ridgeway (1999) \\
\hline 4. & $\begin{array}{l}\text { MARS (multivariate adaptive } \\
\text { regression splines) }\end{array}$ & $\begin{array}{l}\text { A nonparametric regression method, mixing CTA } \\
\text { and GAM. }\end{array}$ & Friedman (1991) \\
\hline 5. & $\begin{array}{l}\text { GAM (generalized additive } \\
\text { model) }\end{array}$ & $\begin{array}{l}\text { A regression method, with } 4 \text { degrees of freedom and } \\
\text { a stepwise procedure to select the most } \\
\text { parsimonious model. }\end{array}$ & Hastie \& Tibshirani (1990) \\
\hline 6. & $\begin{array}{l}\text { MDA (mixture discriminant } \\
\text { analysis) }\end{array}$ & A classification method - based on mixture models. & Hastie \& Tibshirani (1990) \\
\hline 7. & GLM (generalized linear model) & $\begin{array}{l}\text { A regression method, with polynomial terms for } \\
\text { which a stepwise procedure is used to select the } \\
\text { most significant variables. }\end{array}$ & McCullagh \& Nelder (1989) \\
\hline 8. & ANN (artificial neural networks) & $\begin{array}{l}\text { A machine-learning method, with the mean of three } \\
\text { runs used to provide predictions and projections. }\end{array}$ & Ripley (1996) \\
\hline 9. & SER (surface range envelope) & $\begin{array}{l}\text { A simple rectilinear envelope, that takes into account } \\
\text { the whole range of conditions in which the } \\
\text { species is present. }\end{array}$ & Busby (1991) \\
\hline
\end{tabular}

has been used to evaluate the models: $80 \%$ of the presenceabsence stands have been labeled as the training set and the remaining $20 \%$ as the testing set. The number of model evaluation runs was set to three with a repetition of two pseudo-absence combinations on each run, resulting in a total number of six evaluation runs per model.

The models outlined predict suitability values between 0 and 1 at each site. We applied a binary transformation (absence or presence, 0 or 1 ) by assigning a threshold from which we can consider a species present or absent, using the True Skill Statistic (TSS). This threshold represents the optimum correct classification of both presences and absences within the evaluation data. However, the accuracy of each model was calculated using both the AUC [area under the curve, from receiver operating characteristics curve (Swets, 1988)] and TSS (Allouche et al., 2006).

To constrain model uncertainty, averaging of model predictions (giving the same weight to all predictions) can be implemented to derive a consensus prediction; an alternative is to combine models using some form of weighting (e.g. using PCA score value, Thuiller et al., 2003; Araújo \&Guisan, 2006). There is a wide range of approaches to do this (see Araújo \& New, 2007 for a review). In this study, each model is given a weight in the ensemble of forecasts depending on their predictive accuracy using TSS. A decay factor of 1.6 in weights is set; that is, models are ordered in terms of TSS and the weight of each model in the forecast will be 1.6 times larger than the following. This procedure (i.e. a form of 'stacking') ensures accuracy-based discrimination between models. Further information on this procedure may be found in Thuiller et al. (2009).

Climatic and topographic uncorrelated variables (from more than 100 raw variables) are used to apply these nichebased models. For each target species, a different set of topoclimatic variables is chosen by evaluating the correlation matrices. Variables were chosen from those commonly shown to influence tree distribution.

The variables chosen for each species, and their mean relative importance over all niche-based models were:

- Q. ilex - Summer minimum water availability (11\%), mean winter water availability $(31 \%)$, minimum of the mean winter temperature $(23 \%)$, minimum of the mean summer temperature $(12 \%)$, cost-distance to the sea $(15 \%)$, slope $(7 \%)$.

- P. halepensis - Mean spring water availability (40\%), minimum of the mean winter temperature $(23 \%)$, cost-distance to the sea $(23 \%)$, aspect (14\%).

- $P$. sylvestris - Summer minimum water availability (39\%), mean winter water availability (8\%), 
minimum of the mean winter temperature (35\%), cost-distance to the sea $(6 \%)$, slope $(11 \%)$.

The relative importance of each variable is calculated based on the correlation between standard prediction and the prediction with a randomized variable, therefore estimating the influence of the randomized variable in the modeling (see Thuiller et al., 2009 for further details).

\section{Ecosystem model GOTILWA +}

GOTILWA + (Growth Of Trees Is Limited by WAter), (Keenan et al., 2008, 2009a, b, c, 2010; http:/ /www.creaf.uab.es/GOTIL $\mathrm{WA}+$ ) is a process-based terrestrial biogeochemical model of forest growth that has been developed in the Mediterranean region to explore how forests are influenced by water stress, tree stand structure, management techniques, soil properties, and climate (including $\mathrm{CO}_{2}$ ) change.

GOTILWA + does not predict the distribution of a species, but simulates tree growth, and the associated carbon and water fluxes for different tree species in different environments, thus reflecting a site-species specific ecophysiological suitability. The model treats monospecific stands, which can be even or uneven-aged. Individual trees are aggregated into 50 $\mathrm{dbh}$ (diameter at breast height) classes and calculations are performed for each class. Hourly ecosystem carbon and water fluxes are estimated using meteorological forcing. No bioclimatic limits are set in GOTILWA +, and indeed indirect bioclimatic limits can only be considered through the direct effect of climate on the physiological processes of the forest.

The GOTILWA + model includes a two-leaf canopy photosynthetic submodel (Wang \& Leuning, 1998; Dai et al., 2004). The photosynthesis submodel treats the C3 photosynthetic pathway. The canopy is divided into sunlit and shaded leaves, with the amount of intercepted diffuse and direct radiation depending on the time of the day, season, and the area of leaf exposed to the sun (Campbell, 1986). Foliage net assimilation rates are calculated using the Farquhar et al. (1980) photosynthesis model, with dependencies on intercepted quantum flux density, species-specific photosynthetic capacities, leaf temperature, and leaf intercellular $\mathrm{CO}_{2}$ concentration. Stomatal conductance is calculated using the Leuning et al. model (Leuning et al., 1995) that is the advancement of the Ball et al. (1987) model. Net photosynthesis is scaled from the leaf to the canopy through the canopy microclimate model, to give canopy bulk gross primary production (GPP). Net primary production (NPP) is calculated as the balance of GPP less autotrophic respiration components and is defined as $\mathrm{NPP}=A+R_{\mathrm{f}}+R_{\mathrm{w}}+R_{\mathrm{r}}$, where $A$ is the net assimilation rate per unit ground ( $=\mathrm{GPP}$-daytime leaf respiration), $R_{\mathrm{f}}$ is night respiration rate per ground unit area, $R_{\mathrm{w}}$ is respiration of nonleaf aerial plant tissues, $R_{\mathrm{r}}$ is respiration of root tissues. Model parameters were set to species-specific values (as in Gracia et al., 1999; Kramer et al., 2002; Morales et al., 2005; Keenan et al., 2009a). Each tree cohort is represented with three carbon compartments: leaf, sapwood, and fine roots. Available mobile carbon is allocated to each, and maintenance respiration of each compartment is calculated as a function of temperature.
Water stress affects the photosynthesis-conductance coupling by directly reducing the photosynthetic potential through a nonlinear relation to soil water content (Keenan et al., 2009a). Phenology is temperature-dependent and accounted for in an updated version of the Pelkonen \& Hari (1980) approach for calculating the seasonal variations in photosynthetic potential. GOTILWA + has been validated and widely applied both in the Mediterranean region and the rest of Europe (see Kramer et al., 2002; Morales et al., 2005; Keenan et al., 2009a for validation exercises and Keenan et al., 2009b, c, 2010 for example applications).

\section{Experimental setup}

The niche-based model ensemble was used to calculate the per model suitability for each recorded stand $\left(1 \mathrm{~km}^{2}\right.$ scale) for the two periods 1950-1998 and 2050-2080. A weighted mean model ensemble suitability was then calculated for each period. For GOTILWA + , simulations were run for each dominant occurrence of the three studied species for the period 19302100. Two experiments were considered for the GOTILWA + model: (1) with increasing $\mathrm{CO}_{2}$ concentrations as prescribed by the A1 climate scenario, (2) with $\mathrm{CO}_{2}$ concentrations fixed constant at post 2000 levels from 2000 to 2100 . We used modeled values of NPP as a pseudo-proxy for suitability, given that it reflects direct changes in temperature and soil water availability, and as well as more complex indirect effects of changes in phenological events, labile carbon pools, stand biomass and the associated maintenance, growth and turnover. Long- and short-term changes in NPP therefore can be used as a simple representation of the 'health' of a forest stand and may be correlated to changes in suitability values for a given species.

\section{Results}

We first assessed consistency in niche-based model predictions by measuring agreement between modeled present-day distributions and known presence and pseudo-absence of species (Table 2). The results showed a good predictive ability for observed distributions, with most mean AUC and TSS values within ranges of good predictive performance (Allouche et al., 2006). The Random Forest (RF) model performed consistently better across species, followed by the classification tree analysis (CTA) and generalized boosting model (GBM) models. Variability in performance between modeling techniques was high (Table 2), with mean TSS values varying by up to two times between models. The TSS statistic proved to be a more sensitive estimator of model predictive accuracy than the AUC statistic. In the case of TSS, each species weighted model ensemble proved to have higher predictive power than simply taking the average of all models, or even using the best model.

Two distinct groups were observed in the niche-based models: the first consisting of the three methods GAM, GLM, and MDA, and the second group comprising of the three methods MARS, GBM, and CTA. Three methods [artificial neural networks (ANN), RF, and surface range envelope (SRE)] with distinct predictions were observed (Fig. 2) Although the majority of methods show an overall good 
Table 2 Assessment of the agreement between modelled and observed distributions for each niche-based model and species, and the resulting weights used in the multimodel ensemble

\begin{tabular}{|c|c|c|c|c|c|c|c|c|c|}
\hline \multirow{2}{*}{$\begin{array}{l}\text { Modeling } \\
\text { techniques }\end{array}$} & \multicolumn{3}{|c|}{ Quercus ilex } & \multicolumn{3}{|c|}{ Pinus halepensis } & \multicolumn{3}{|c|}{ Pinus sylvestris } \\
\hline & Weight & AUC & TSS & Weight & AUC & TSS & Weight & AUC & TSS \\
\hline $\mathrm{RF}$ & 0.381 & $\begin{array}{c}0.974 \\
(0.004)\end{array}$ & $\begin{array}{c}0.845 \\
(0.011)\end{array}$ & 0.381 & $\begin{array}{c}0.962 \\
(0.006)\end{array}$ & $\begin{array}{c}0.805 \\
(0.018)\end{array}$ & 0.381 & $\begin{array}{c}0.989 \\
(0.002)\end{array}$ & $\begin{array}{c}0.911 \\
(0.012)\end{array}$ \\
\hline CTA & 0.238 & $\begin{array}{c}0.931 \\
(0.01)\end{array}$ & $\begin{array}{c}0.768 \\
(0.02)\end{array}$ & 0.238 & $\begin{array}{c}0.924 \\
(0.011)\end{array}$ & $\begin{array}{c}0.750 \\
(0.019)\end{array}$ & 0.220 & $\begin{array}{c}0.963 \\
(0.008)\end{array}$ & $\begin{array}{c}0.876 \\
(0.019)\end{array}$ \\
\hline GBM & 0.149 & $\begin{array}{c}0.947 \\
(0.006)\end{array}$ & $\begin{array}{c}0.770 \\
(0.014)\end{array}$ & 0.149 & $\begin{array}{c}0.954 \\
(0.006)\end{array}$ & $\begin{array}{c}0.779 \\
(0.013)\end{array}$ & 0.160 & $\begin{array}{c}0.984 \\
(0.004)\end{array}$ & $\begin{array}{c}0.881 \\
(0.014)\end{array}$ \\
\hline MARS & 0.093 & $\begin{array}{c}0.929 \\
(0.01)\end{array}$ & $\begin{array}{c}0.714 \\
(0.02)\end{array}$ & 0.073 & $\begin{array}{c}0.943 \\
(0.005)\end{array}$ & $\begin{array}{c}0.750 \\
(0.010)\end{array}$ & 0.100 & $\begin{array}{c}0.981 \\
(0.005)\end{array}$ & $\begin{array}{c}0.881 \\
(0.012)\end{array}$ \\
\hline GAM & 0.031 & $\begin{array}{c}0.893 \\
(0.008)\end{array}$ & $\begin{array}{c}0.643 \\
(0.012)\end{array}$ & 0.078 & $\begin{array}{c}0.942 \\
(0.006)\end{array}$ & $\begin{array}{c}0.755 \\
(0.010)\end{array}$ & 0.055 & $\begin{array}{c}0.978 \\
(0.004)\end{array}$ & $\begin{array}{c}0.873 \\
(0.008)\end{array}$ \\
\hline MDA & 0.054 & $\begin{array}{c}0.890 \\
(0.012)\end{array}$ & $\begin{array}{c}0.668 \\
(0.028)\end{array}$ & 0.021 & $\begin{array}{c}0.901 \\
(0.018)\end{array}$ & $\begin{array}{c}0.699 \\
(0.024)\end{array}$ & 0.020 & $\begin{array}{c}0.871 \\
(0.007)\end{array}$ & $\begin{array}{c}0.861 \\
(0.014)\end{array}$ \\
\hline GLM & 0.032 & $\begin{array}{c}0.890 \\
(0.009)\end{array}$ & $\begin{array}{c}0.645 \\
(0.015)\end{array}$ & 0.036 & $\begin{array}{c}0.933 \\
(0.007)\end{array}$ & $\begin{array}{c}0.737 \\
(0.017)\end{array}$ & 0.035 & $\begin{array}{c}0.976 \\
(0.004)\end{array}$ & $\begin{array}{c}0.867 \\
(0.006)\end{array}$ \\
\hline ANN & 0.010 & $\begin{array}{c}0.754 \\
(0.037)\end{array}$ & $\begin{array}{c}0.475 \\
(0.048)\end{array}$ & 0.016 & $\begin{array}{c}0.903 \\
(0.008)\end{array}$ & $\begin{array}{c}0.706 \\
(0.012)\end{array}$ & 0.021 & $\begin{array}{c}0.963 \\
(0.016)\end{array}$ & $\begin{array}{c}0.847 \\
(0.021)\end{array}$ \\
\hline SRE & 0.013 & - & $\begin{array}{c}0.528 \\
(0.015)\end{array}$ & 0.009 & - & $\begin{array}{c}0.436 \\
(0.030)\end{array}$ & 0.009 & - & $\begin{array}{c}0.683 \\
(0.022)\end{array}$ \\
\hline Ensemble forecasting & - & $\begin{array}{c}0.958 \\
(0.003)\end{array}$ & $\begin{array}{c}0.961 \\
(0.003)\end{array}$ & - & $\begin{array}{c}0.969 \\
(0.001)\end{array}$ & $\begin{array}{c}0.976 \\
(0.001)\end{array}$ & - & $\begin{array}{c}0.990 \\
(0.486)\end{array}$ & $\begin{array}{r}0.990 \\
(0.513)\end{array}$ \\
\hline
\end{tabular}

Statistics given are the area under the curve (AUC) and the true skill statistic (TSS). Values given in brackets are the associated standard deviations. Accuracy classification for AUC: $1>\operatorname{good}>0.8>$ fair $>0.7>$ poor; TSS: $1>\operatorname{good}>0.6>$ fair $>0.4>$ poor $($ see BIOMOD Manual).

$\mathrm{RF}$, random forest; CTA, classification tree analysis; GBM, generalized boosting model; MARS, multivariate adaptive regression splines; GAM, generalized additive model; MDA, mixture discriminant analysis; GLM, generalized linear model; ANN, artificial neural networks; SRE, surface range envelope.

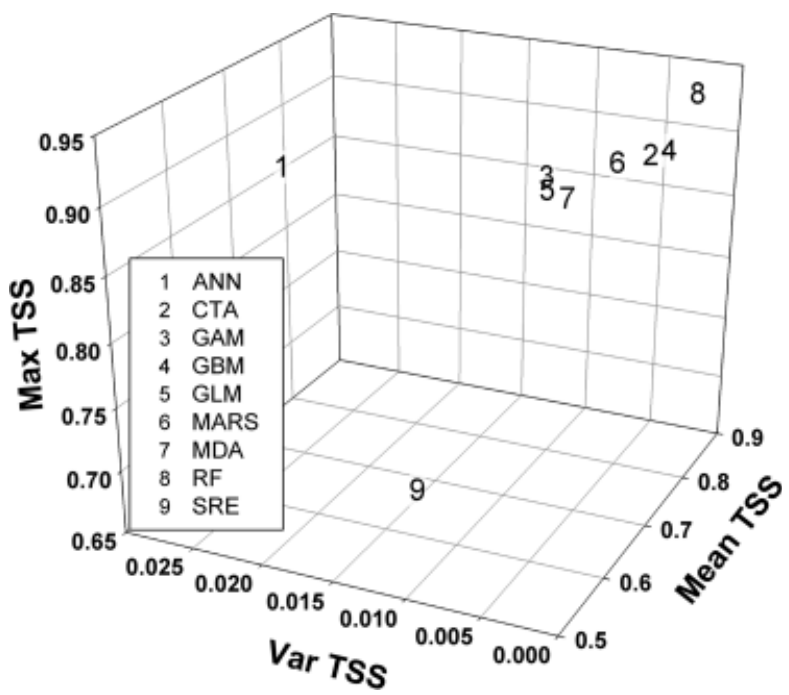

Fig. 2 Model performance as measured by the true skill statistic (TSS) through the mean, maximum and variance of the TSS.

performance of mean TSS across species, they vary in terms of TSS variance across species. The RF model proved to be the most stable across species due to its flexibility in contrast with
SRE, a restricted envelope only based on maximum and minimum of the explanatory variables. ANN accounts for the greatest variance due to its performance for $Q$. ilex (Table 2).

When predicting responses to climate change, a broad topoclimatic range of responses were observed (Fig. 3), although all species showed the same general tendency. Model ensemble predictions of suitability showed large declines in suitability for each of the three species between the periods 2050-2080 and 1950-1980. Q. ilex stands were the largest affected by the applied climate change scenario (Fig. 4), with $40.4 \%$ of current stand locations becoming unsuitable by the period 2050-2080. Although Q. ilex is a typical Mediterranean species, and relatively drought tolerant, its large topoclimatic distribution means that it is currently located in some areas which are predicted to be subject to high levels of climate change in the future. Thus, areas of its southern most range were the highest affected. Climate change induced decline of $P$. halepensis was not so severe, with the majority of sites $(87.3 \%)$ maintaining a level of suitability that would permit the presence of the species. The multimodel ensemble also predicted an important decline in the presence of $P$. sylvestris (24\%), though the species maintained a strong presence in most mountainous regions (e.g. the Pyrenees Mountains), resulting in much larger geographical variability than that observed for the other two species. 


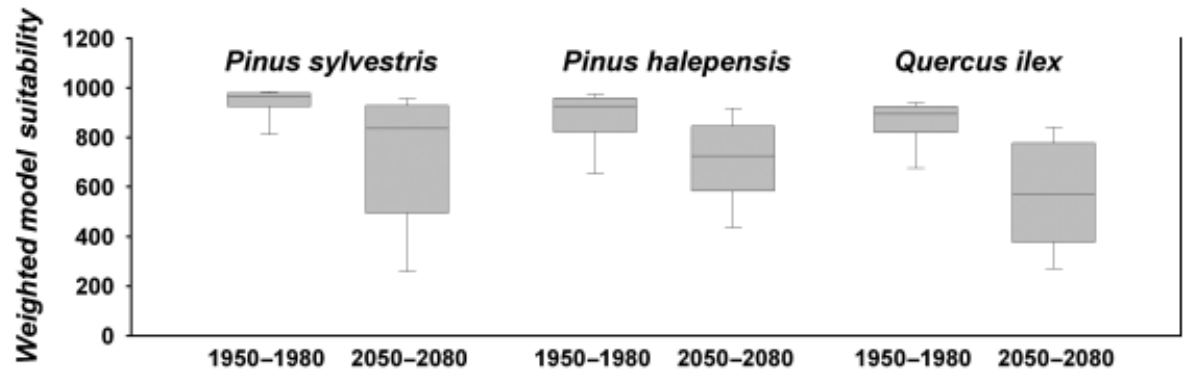

Fig. 3 Weighted modelled suitability for current presence distribution of each species during the period 1950-1980 and the projected weighted model suitability for the same forest stands for the period 2050-2080 under the A1fi scenario of the HADCM3 model climate predications.
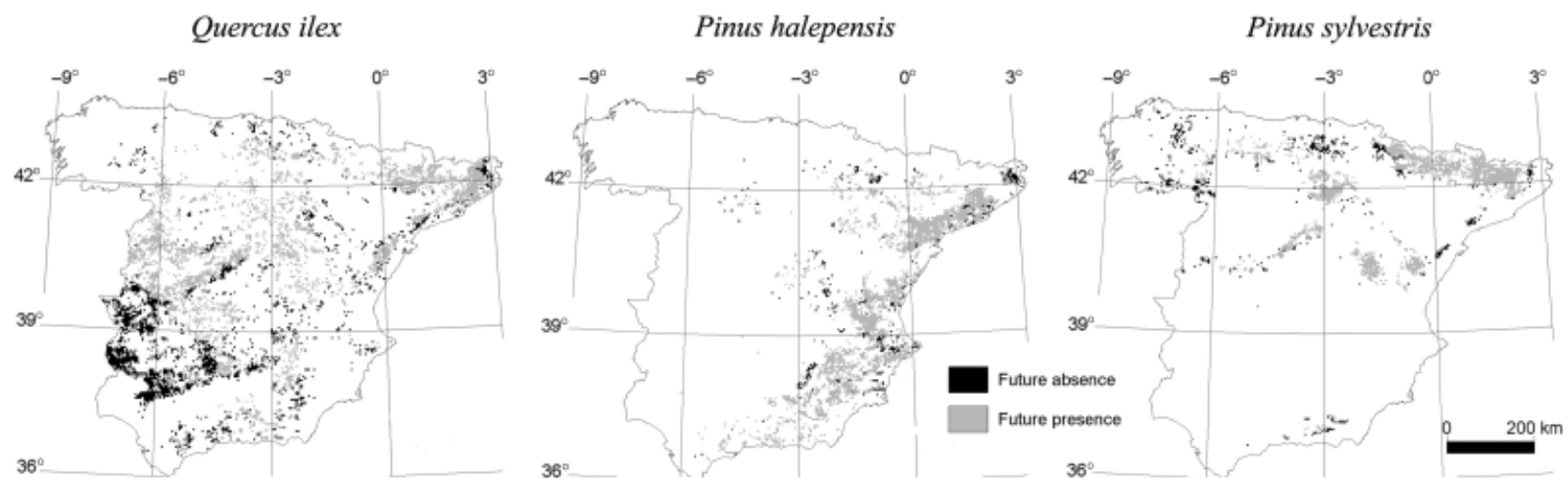

Fig. 4 Predicted future of current forests of Quercus ilex, Pinus halepensis, and P. sylvestris in continental Spain, as predicted by the multimodel ensemble for the period 2050-2080. Future absence relates to current forest stands in locations which are projected to be geoclimatically unsuitable by the period 2050-2080.

Table 3 Percentage (\%) of current forest stands which were predicted to become unsuitable for their current species by the period 2050-2080 according to the different statistical models

\begin{tabular}{lccccccrrrrr}
\hline & ANN & CTA & GAM & GBM & GLM & MARS & MDA & RF & SRE & Mean & SD \\
\hline Quercus ilex & 5.65 & 46.97 & 21.34 & 40.06 & 16.92 & 29.10 & 9.66 & 30.56 & 88.42 & 32.08 & 25.0 \\
Pinus halepensis & 18.59 & 9.50 & 30.62 & 18.40 & 20.51 & 21.49 & 27.94 & 6.60 & 47.13 & 22.31 & 12.0 \\
Pinus sylvestris & 34.99 & 28.39 & 23.16 & 15.97 & 27.94 & 3.06 & 29.23 & 14.34 & 51.21 & 25.37 & 13.7 \\
Mean & 19.74 & 28.29 & 25.04 & 24.81 & 21.79 & 17.88 & 22.28 & 17.17 & 62.25 & \\
SD & 14.7 & 18.7 & 4.92 & 13.2 & 5.6 & 13.3 & 10.9 & 12.2 & 22.7 & \\
\hline
\end{tabular}

The per-species and per-model mean and standard deviation (SD) are also given.

ANN, artificial neural networks; CTA, classification tree analysis; GAM, generalized additive model; GBM, generalized boosting model; GLM, generalized linear model; MARS, multivariate adaptive regression splines; MDA, mixture discriminant analysis; RF, random forest; SRE, surface range envelope.

Results for estimates of change in current forests under future climates also demonstrate that the modeling technique used to define climate envelopes can have a very large impact on predictions (Table 3). Predictions for each of the three species (excluding SRE which presents a very low weight) varied in magnitude of predicted change. For example, for Q. ilex predicted losses of current habitat ranged from $5.6 \%$ to $46.9 \%$. The other two species showed a lower range of model dependent variability (between 3\% and 35\%). Between-model variability across species was also very high, with models predicting between 17\% (MARS model) and 28.3\% (CTA model) loss of current habitat on average over the three species by the period 2050-2080.

Simulations using the GOTILWA + model showed a quite stable productivity from the three species over the past century (Fig. 5), with slight increases in production nearing the end of the century. When considering potential future climatic change with no increment in atmospheric $\mathrm{CO}_{2}$ each of the 

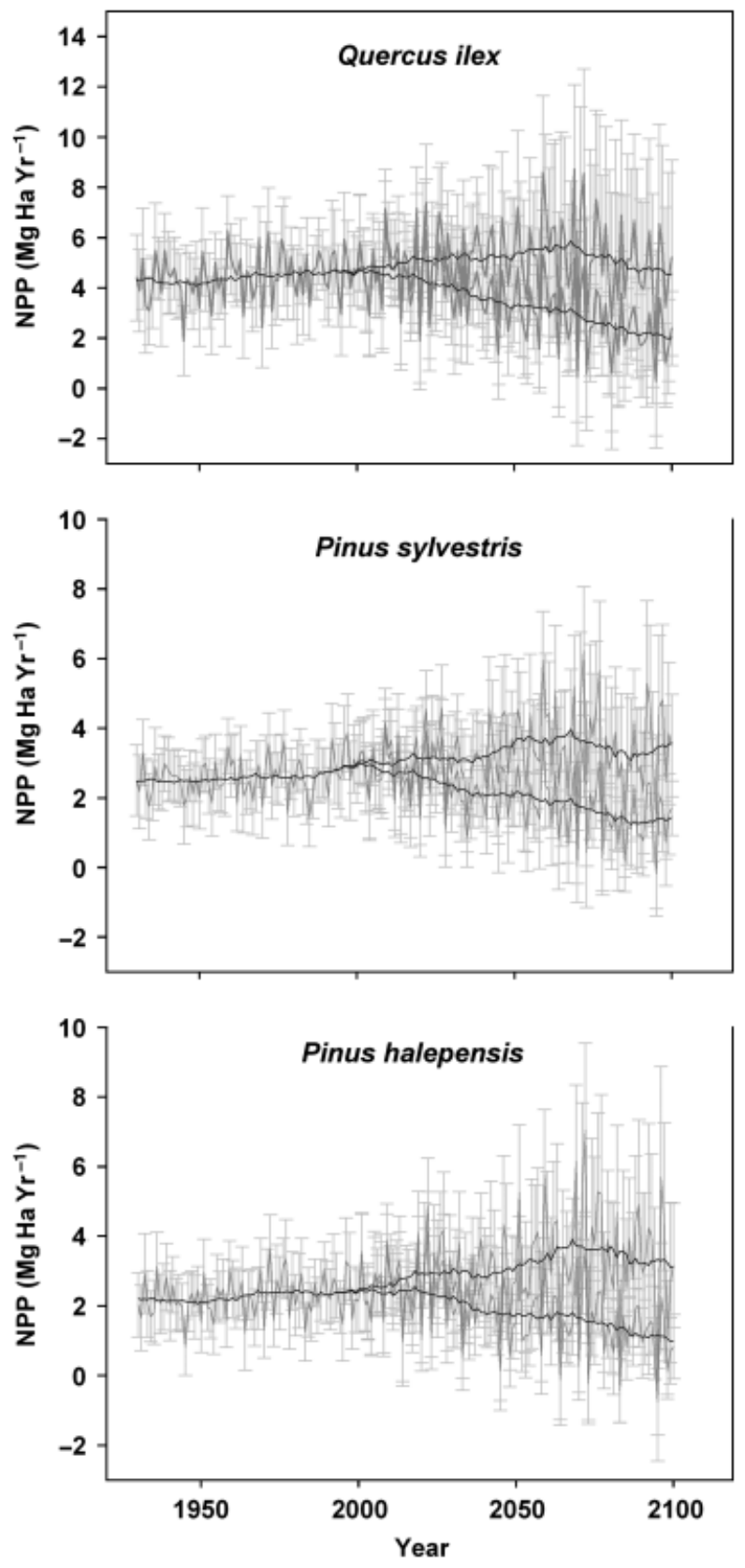

Fig. 5 Mean and standard deviation simulated annual net primary production (NPP, $\mathrm{MgC} \mathrm{ha}{ }^{-1} \mathrm{yr}^{-1}$ ) for dominant species forested pixels from 1930 to 2100 using the GOTILWA + model, both with and without a future $\mathrm{CO}_{2}$ increment, for each of the three species. Solid lines reflect the running average of 15 years. The upper regression line in each panel refers to simulations with a $\mathrm{CO}_{2}$ increment, whereas the lower line refers to simulations with no increment in $\mathrm{CO}_{2}$ after the year 2000.

species was predicted to reduce their production (NPP) on average by the time period 2050-2080 (Fig. 5). This supports the results from the niche-based modeling approach, given that a reduced productivity reflects a reduction in topoclimatic suitability for these species. However, when considering the effect of increasing atmospheric $\mathrm{CO}_{2}$ concentrations, simulated production from each of the three species showed strong increases in NPP until about 2070. After 2070, the fertilization effect of increased atmospheric $\mathrm{CO}_{2}$ was observed to plateau, and species-specific reductions in NPP were observed. $P$. halepensis showed the strongest reduction, followed by Q. ilex. Although NPP rates began to decline by the end of the 21st century under the $\mathrm{CO}_{2}$ fertilization scenario, they still maintained higher average rates (if only slightly in the case of Q. ilex) than those observed during the period 1950-1980.

Large differences were observed between the response of the species as modeled by GOTILWA + and that of the multimodel ensemble. However, when considering spatially explicit simulations with a constant $\mathrm{CO}_{2}$, the per-pixel magnitude and direction of the changes in NPP and in suitability (as predicted by the multimodel ensemble) between the period 2050-2080 and 1950-1980 were similar for two (Q. ilex, P. sylvestris) of the three species (Fig. 6). So, less suitability for a pixel (nichebased) was reflected in less NPP for the same site, if no $\mathrm{CO}_{2}$ effect is taken into account (process-based). On the other hand, when considering a $\mathrm{CO}_{2}$ increment in the GOTILWA + simulations, NPP generally showed an increase. The same per-pixel spatial trend was maintained, where low suitability was mirrored by low NPP for Q. ilex and P. sylvestris, but the sign of the relative change in NPP vs. that of suitability, between the two focus periods, was different.

The root mean squared error (RMSE) between the two different modeling approaches increased by a factor of three between GOTILWA + simulations considering atmospheric $\mathrm{CO}_{2}$ as constant and those considering a $\mathrm{CO}_{2}$ increment. This indicates that the introduction of $\mathrm{CO}_{2}$ as a driver in the GOTILWA model lead to a large dissimilarity between the two modeling approaches. For GOTILWA + simulations with a constant $\mathrm{CO}_{2}$ concentration, the RMSE between the percentage of change in NPP and that of suitability for the two periods was $0.22,0.28$, and 0.29 for $Q$. ilex, P. Sylvestris, and $P$. halepensis, respectively. The RMSE when considering a $\mathrm{CO}_{2}$ increment was 0.64, 0.73, and 0.83 (data presented in Fig. 6). Changes in NPP and suitability are not necessarily $1: 1$ correlated, but the RMSE between the estimates gives a measure of their similarity, and the extent of the relative dissimilarity introduced by the consideration of the potential effect of $\mathrm{CO}_{2}$ fertilization.

\section{Discussion}

We found that the applied niche-based models were capable of capturing the complex topoclimatic distribution of the three studied species, and that the use of a weighted multimodel ensemble improved the individual model performance. This adds to the mounting evidence that environmental conditions strongly influence species distribution patterns locally and regionally, as they do world-wide (Hawkins et al., 2003). Indeed, most of the selected variables were related to water and energy, which is consistent with the widely documented trend of plant species to be climatically driven by 

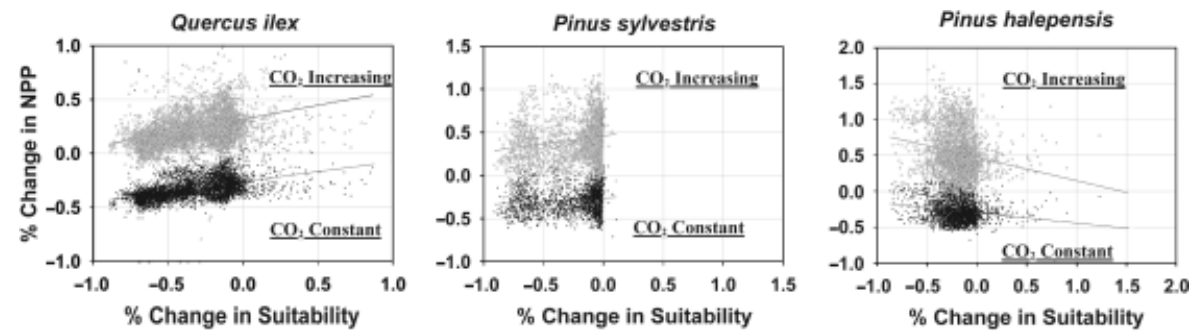

Fig. 6 The spatially explicit change (percentage per pixel) in average per period net primary production (NPP) (GOTILWA + ) and estimated Suitability (multi-niche-based model ensemble), between the periods 1950-1980 and 2050-2080, considering both GOTIL$\mathrm{WA}+$ simulations with (gray) and without (black) an atmospheric $\mathrm{CO}_{2}$ increment. Lines represent linear regressions.

water-energy dynamics (see e.g., Field et al., 2005 and references therein).

An important issue regarding niche modeling is the variability of results when using different modeling techniques (Thuiller et al., 2003; Araújo et al., 2005a, b; Pearson et al., 2006). The identification of five distinct patterns of range prediction from nine models highlights the differences between modeling approaches, while providing a foundation for further investigation as to which technique, or group of techniques, may be most appropriate for predicting future ranges but inevitably calls for an ensemble forecasting to determine species distributions (Araújo \& New, 2007). The best performing models are not always the same for different species, even if some of them (in particular RF, CTA, GBM) generally perform better for the species included in this study. The performance also varied according to the number of available presence records, corroborating results of other studies (Elith et al., 2006). Nevertheless, the use of different niche-based models has been shown here to be an effective manner by which to quantify the inherent intermodel variability (Araújo et al., 2005a, b; Thuiller et al., 2005) and improve model estimates through ensemble forecast techniques. Process-based models would also benefit from such an approach, and future comparison studies should incorporate multiple process-based models.

All models, considered in any time period, entail multiple sources of uncertainty (Thuiller et al., 2003; Guisan \& Thuiller, 2005). Many important biological factors are either often insufficiently described or omitted in all modeling approaches (see Guisan \& Thuiller, 2005), such as small-scale environmental heterogeneity (e.g. microclimates, quantitative properties of soils), local dispersal (local dispersal leads to intraspecific aggregation; Pacala, 1997); biotic interactions across trophic levels (e.g. dispersal, pollinization; Araújo \& Luoto, 2007); and processes that fragment space and create patchy aggregated distributions (e.g. forest fire events) (Fahrig, 2003). Perhaps most fundamentally for projecting possible future scenarios, large uncertainty exists regarding direct impacts of increased concentrations of atmospheric $\mathrm{CO}_{2}$ on species physiology and competitive interactions (e.g. Ainsworth et al., 2008).

Despite their broad use, uncertainties about nichebased model predictions remain high (Hampe, 2004; Heikkinen et al., 2006; Randin et al., 2006). To date, the main drawback of niche-based models is their inability to consider important relationships such as biotic interactions, mortality, or growth (Davis et al., 1998; Hampe, 2004) and their reliance on observed distributions, which are the results of long-term historical factors (e.g., postglacial recolonization and human management), and environmental stochasticity, among other factors. As they are empirical models they are based on information relevant to present day or past species distributions. This may make their extrapolation to future scenarios questionable for some species and drivers (e.g. terrestrial vegetation and $\mathrm{CO}_{2}$ fertilization) (Guisan \& Thuiller, 2005; Pearson et al., 2006; Rickebusch et al., 2008). One technique to reduce prediction uncertainty is to fit ensembles of forecasts by simulating across more than one set of initial conditions, model classes, model parameters, and boundary conditions (see Araújo \& New, 2007, for a review) and analyze the resulting range of uncertainties with probabilistic methodologies rather than using a single modeling outcome (Thuiller et al., 2006a, b; Araújo \& New, 2007). Another may be to compare results from niche-based models to those from process-based ones (e.g. Morin \& Thuiller, 2009). In this study, we have shown both these techniques to be valuable in reducing and highlighting uncertainty.

The use of species level process-based models is complicated by their necessity for a large amount of data to be calibrated (often leading to the use of proxies, assumptionsm and expert knowledge), and large computational resources. Applications are thus restricted to well-known species for which demography or 
physiology has been sufficiently studied. Previous studies have highlighted large differences between different process-based model approaches (e.g., Kramer et al., 2002) and systematic difficulties in some ecosystems (Morales et al., 2005), for example, difficulties in representing soil water and soil water stress (Jung et al., 2007), or accurately predicting phenology (Keenan et al., 2009a) and related uncertainties in predicting changes to the length of the growing season. Although process-based models should theoretically be more reliable than empirical models under future climate scenarios, not all processes are fully understood (e.g., species adaptation, down-regulation, nitrogen cycling etc.), potentially also making their extrapolation to future scenarios questionable. Such uncertainties can be effectively explored through techniques such as Monte Carlo parameter estimation (e.g., Richardson et al., 2010), normally showing poorly constrained respiration processes, but well constrained canopy photosynthesis and growth. Multimodel suites, similar to that of BIOMOD, are not used for process-based models but could help reduce such uncertainties.

The effect of elevated $\mathrm{CO}_{2}$ has been highlighted as the largest uncertainty in projecting future productivity of terrestrial vegetation (Parry et al., 2004). Elevated $\mathrm{CO}_{2}$ stimulates photosynthetic carbon gain and net primary production over the long term despite down-regulation of Rubisco activity. It also improves nitrogen-use efficiency at both the leaf and canopy scale, while stimulating dark respiration via a transcriptional reprogramming of metabolism (Leakey et al., 2009). Experimental results indicate that plants are able to increase their water-use efficiency (WUE) as $\mathrm{CO}_{2}$ levels rise (e.g., Picon et al., 1996; Morison, 1998), as has been corroborated under field conditions (Peñuelas \& Azcón-Bieto, 1992; Ehrlinger \& Cerling, 1995; Duquesnay et al., 1998; Gunderson et al., 2002; Ainsworth \& Rogers, 2007). Studies have also identified interspecies variability in responses to increasing atmospheric $\mathrm{CO}_{2}$ concentrations (e.g., Francey \& Farquhar, 1982), and, importantly, have highlighted the possibility of species-specific response saturation rates (Waterhouse et al., 2004; Betson et al., 2007). Few interspecies comparisons exist, though the general tendencies have been shown to be conserved over a large number of species (Hickler et al., 2008). It should be noted, however, that there is broad agreement that the effects of elevated $\mathrm{CO}_{2}$ measured in experimental settings lacking potentially limiting influence of pests, weeds, nutrients, competition for resources, soil water, and air quality, may overestimate field responses of terrestrial vegetation (Long et al., 2006; Easterling et al., 2007; Tubiello et al., 2007; Ainsworth et al., 2008; Zavala et al., 2008).
Although soil water availability is the largest limitation to forest growth in Mediterranean climate regions (Allen, 2001) [and often badly represented in model projections (Hickler et al., 2009)], fertilization studies show that the availability of nutrient availability limits primary production in Mediterranean ecosystems (LeBauer \& Treseder, 2008; Elser et al., 2007). Nitrogen deposition is expected to increase in Mediterranean regions in the future (Rodà et al., 2002), but nitrogen limitation is also expected to become more pronounced as atmospheric $\mathrm{CO}_{2}$ concentration increases (the 'progressive nitrogen limitation' hypothesis) (Luo et al., 2004, 2006; de Graaff et al., 2006; Finzi et al., 2007; Reich et al., 2006). Biogeochemical models have recently incorporated dynamic nitrogen cycles (e.g., Zaehle \& Friend, 2010) and results show that $\mathrm{C}-\mathrm{N}$ interactions significantly reduce the stimulation of forest NPP under increased atmospheric $\mathrm{CO}_{2}$ concentrations (e.g., Thornton et al., 2007; Jain et al., 2009). Such down-regulation in the response of forest productivity under elevated $\mathrm{CO}_{2}$ (Ainsworth \& Rogers, 2007) is estimated at about $10 \%$ for European forest species (Medlyn \& Jarvis, 1999). It is thus likely that the projected future NPP (under the $\mathrm{CO}_{2}$ enriched scenario) is overestimated in this study because it does not properly account for $\mathrm{N}$ down-regulation constraints (Hungate et al., 2003; Thornton et al., 2007).

Organisms are the products of chemical reactions, and their development, growth and mortality depends on various environmental factors, in particular temperature, radiation, $\mathrm{CO}_{2}$, nutrients, and water availability. In the Mediterranean region, the future presence of a species is thus likely determined by the complex balance of temperature change, water stress. and the species-specific capacities (e.g. Peñuelas et al., 2008). Ultimately, species-specific responses may affect the structure and functioning of ecosystems (Peñuelas \& Filella, 2001) due to altered competitive relationships of key performance measures and the loss of synchronization of development (Fitter \& Fitter, 2002; Gordo \& Sanz, 2005). This could strongly contribute to relative fitness and thus to evolving biogeographic distributions.

The magnitude of climate change scenarios for past and future periods differ among different circulation models and therefore it is a source of uncertainty that might affect the results of the applied models (Beaumont et al., 2008; Parra \& Monahan, 2008). It is therefore normally of utmost importance to apply a range of climate models and scenarios in order to estimate the inherent variability introduced by the choice of climate. In this study, due to computational limitations associated with the application of a mechanistic process-based model, we have applied only one climate scenario and model. Although the use of other climate 
data would change the projected distribution for each of the species, and the productivity patterns simulated by the mechanistic process-based model, we argue that the qualitative conclusions of this work are independent of the choice of climate scenario.

The presented results show that previous reports of species decline in continental Spain (e.g. Benito-Garzon et al., 2008) may be overestimated due to two reasons: the use of only one predictive niche-based model, and the failure to account for possible effects of $\mathrm{CO}_{2}$ fertilization. Similar studies in other regions, which do not consider these two aspects, are also potentially overestimating species decline due to climate change. Similarly, the presented niche-based model results also likely overestimate the decline in suitability.

Human effects can have large impacts on the distribution of species (Channel \& Lomolino, 2000). The assumption of equilibrium between a species distribution and environmental conditions is less valid in disturbed ecosystems such as Mediterranean forests, where human influence is strong (e.g., land-use effects, fire occurrences). It has also been reported that many European tree species are not in equilibrium with climate (Svenning \& Skov, 2004, not P. sylvestris, which was reported to be in relative equilibrium) as a consequence of postglacial dispersal limitations (Svenning et al., 2008). In this study, some of the observed imbalance between environment and spatial aggregation of tree species might be explained by the lack of equilibrium between species and current environmental conditions. It is also important to bear in mind that our results are restricted to tree species in continental Spain, and thus we can not be certain to what extent any patterns or results that we observe here may be either affected by species occurrences in other regions, or extrapolated to other topoclimatic scenarios.

It is interesting and reassuring that changes in suitability predicted by the niche-based models conferred well with changes in NPP projected by the GOTIL$\mathrm{WA}+$ model (with no $\mathrm{CO}_{2}$ increment) for two of the three studied species. This was not the case, however for $P$. halepensis. This could be explained by the fact that $P$. halepensis is distributed along the coast (Fig. 1). Many factors other than climate can significantly influence species distributions and distribution changes (Hampe, 2004; Coudun et al., 2006; Pearson et al., 2006) and distance from the sea is used as a strong explanatory factor for presence prediction of $P$. halepensis in the niche-based models, which is not the case for the other two species. As distance from the sea is constant under climate change, this could also explain why $P$. halepensis is predicted to loose less of its current territory by the period 2050-2080 due to climate change, when compared with the other species (Table 3), and could in part explain the difference between projects from the niche-based models and those of GOTILWA + for P. halepensis.

Ecosystems in the Mediterranean basin are prone to experience a concatenation of stochastic disturbances, including fire, drought, clearing, grazing, and land-use change. Mediterranean Basin ecosystems are thus characterized by a certain 'unpredictability' (Blondel \& Aronson, 1999). This conditions local adaptation and manifests its effect on the phenotypic variation of forest tree species in response to macroenvironmental gradients (Volis et al., 2002). Adaptive modes could be highly important for predicting future species responses to climate change. The models presented here assume nonsignificant evolutionary and/or ecological change in a species in response to changing environmental conditions through time [thus ignoring rapid in situ adaptation (Thomas et al., 2001), and existing adaptation of populations to local conditions (Hampe, 2004), etc.]. Evidence suggests that species adaption has occurred for many species (Pearman et al., 2008), implying a questionable ability of models to project species responses to potential future climates. However, we are far from a comprehensive understanding of possible species-specific adaptation capacities.

The identification of a general connection between biogeochemistry, plant physiology, disturbance, and species distributions would constitute a considerable advance in our predictive ability (Morin et al., 2007; Chown \& Gaston, 2008). Here we take the first step in using a biogeochemical model in comparison with a niche-based model, estimates of species distributions. Further work is needed to identify complementary elements of the different modeling approaches, in order to develop effective techniques for estimating species responses to potential climate change.

\section{Conclusions}

Plant physiology, biogeography, and related areas of research are currently merging to a new framework for understanding the patterns of the distribution of life on Earth. Ecosystem responses to climate change are driven by complex multifactor influences (Norby \& Luo, 2004; Körner, 2006). An organism's niche must therefore be modeled mechanistically if we are to fully explain distribution limits (Kearney, 2006), especially when considering an organism's distribution under novel circumstances not used for the parameterization of the original model, such as a species introduction or climate change (Guisan \& Thuiller, 2005). We have shown that niche-based models give accurate predictions of present species distributions (which can be improved through the use of multi model ensembles) and that comparisons with a process-based biogeochemical model can 
be useful in highlighting areas of uncertainty in projections under potential climate change. However, given the high variation in the accuracy of model predictions and the species-specific nature of biological responses to landscape changes (e.g. species responses to $\mathrm{CO}_{2}$ fertilization), it seems clear that we are far from a comprehensive methodology for predicting the responses of individual species (and thus current stands) to future climatic change. Our results support recent calls for a new generation of more biologically realistic niche-based models (Guisan \& Thuiller, 2005; Kearney, 2006; Araújo \& Luoto, 2007; Keith et al., 2008; Rickebusch et al., 2008; Montoya et al., 2009; Nogues-Bravo, 2009). Perhaps most importantly, it is vital that models such as those used in this study are interpreted as tools for sharpening our understanding of species range constraints, and that they are only applied in a predictive capacity along with full appreciation of the uncertainty involved.

\section{Acknowledgements}

This work was enabled by support received from the Consolider Montes project (CSD2008-00040) and the Spanish 'Ministerio de Ciencia y Tecnología' projects (CGL2006-01293/BOS and CGL2009-08191). T. K. acknowledges further support from the CCTAME (FP7 212535) project. Data was supplied by the ALARM (FP5 GOCECT-2003-506675) and the ATEAM (FP5 EVK2-2000-00075) project. M. N. acknowledges support from the Grup de mètodes i aplicacions de teledetecció i sistemes d'informació geogràfica (2009 SGR 1511) and S. S. from the project Grup de Qualitat 2009 SGR 247. Many thanks to all those involved in the third Spanish National Forest Inventory, and three anonymous reviewers whose comments greatly improved the manuscript. Computational resources used in this work were kindly provided by the Oliba project of the Universitat Autonoma de Barcelona.

\section{References}

Ainsworth EA, Leakey ADB, Ort DR, Long SP (2008) FACE-ing the facts: inconsistencies and interdependence among field, chamber and modeling studies of elevated $\left[\mathrm{CO}_{2}\right]$ impacts on crop yield and food supply. New Phytologist, 179, 5-9.

Ainsworth EA, Long SP (2005) What have we learned from 15 years of free-air $\mathrm{CO}_{2}$ enrichment (FACE)? A meta-analytic review of the responses of photosynthesis, canopy properties and plant production to rising $\mathrm{CO}_{2}$. New Phytologist, 165, $351-372$

Ainsworth EA, Rogers A (2007) The response of photosynthesis and stomatal conductance to rising $\left[\mathrm{CO}_{2}\right]$ : mechanisms and environmental interactions. Plant, Cell and Environment, 30, 258-270.

Allen HD (2001) Mediterranean Ecogeography. Prentice-Hall, London.

Allouche O, Tsoar A, Kadmon R (2006) Assessing the accuracy of species distribution models: prevalence, kappa and the true skill statistic (TSS). Journal of Applied Ecology, 43, 1223-1232.

Araújo MB, Cabeza M, Thuiller W, Hannah L, Williams P (2004) Would climate change drive species out of reserves? An assessment of existing reserve-selection methods. Global Change Biology, 10, 1618-1626.

Araújo MB, Guisan A (2006) Five (or so) challenges for species distribution modelling. Journal of Biogeography, 33, 1677-1688.

Araújo MB, Luoto M (2007) The importance of biotic interactions for modelling species distributions under climate change. Global Ecology and Biogeography, 16, 743-753.
Araújo MB, Miquel B, Whittaker RJ, Ladle RJ, Erhard M (2005a) Reducing uncertainty in projections of extinction risk from climate change. Global Ecology and Biogeography, 14, 529-538.

Araújo MB, New M (2007) Ensemble forecasting of species distributions. Trends in Ecology and Evolution, 22, 42-47.

Araújo MB, Pearson RG, Thuiller W, Erhard M (2005b) Validation of species-climate impact models under climate change. Global Change Biology, 11, 1504-1513.

Bakkenes M, Alkemade J, Ihle F, Leemans R, Latour JB (2002) Assessing effects of forecasted climate change on the diversity and distribution of European higher plants for 2050. Global Change Biology, 8, 390-407.

Ball JT, Woodrow IE, Berry JA (1987) A model predicting stomatal conductance and its contribution to the control of photosynthesis under different environmental conditions. In: Progress in Photosynthesis Research (ed. Biggins J), pp. 221-224. MartinusNijhoff Publishers, Dordrecht, the Netherlands.

Beaumont LJ, Hughes L, Pitman AJ (2008) Why is the choice of future climate scenarios for species distribution modelling important? Ecology Letters, 11, 1135-1146.

Beaumont LJ, Pitman AJ, Poulsen M, Hughes L (2007) Where will species go? Incorporating new advances in climate modelling into projections of species distributions. Global Change Biology, 13, 1368-1385.

Benito-Garzon M, Sánchez de Dios R, Sainz Ollero H (2008) Effects of climate change on the distribution of Iberian tree species. Applied Vegetation Science, 11, 169-178.

Betson NR, Johannisson C, Löfvenius MO, Grip H, Granström A, Högberg P (2007) Variation in the delta ${ }^{13} \mathrm{C}$ of foliage of Pinus sylvestris $\mathrm{L}$. in relation to climate and additions of nitrogen: analysis of a 32-year chronology. Global Change Biology, 13, 2317-2328.

Blondel J, Aronson J (1999) Biology and Wildlife of the Mediterranean Region. Oxford University Press, Oxford, UK.

Breiman L (2001) Random forests. Machine Learning, 45, 5-32.

Breiman L, Friedman JH, Olshen RA, Stone CJ (1984) Classification and Regression Trees. Chapman \& Hall, New York

Briceño-Elizondo R, Garcia-Gonzalo J, Peltola H, Matala J, Kellomaki S (2006) Sensitivity of growth of Scots pine, Norway spruce and silver birch to climate change and forest management in boreal conditions. Forest Ecology and Management, 232, 152-167.

Bugmann H (2001) A review of forest gap models. Climatic Change, 51, 259-305.

Busby JR (1991) BIOCLIM - a bioclimate analysis and prediction system. In: Nature Conservation: Cost Effective Biological Surveys and Data Analysis (eds Margules CR, Austin MP), pp. 64-68. CSIRO, Canberra.

Campbell GS (1986) Extinction coefficients for radiation in plant canopies calculated using an ellipsoidal inclination angle distribution. Agricultural and Forest Meteoro$\log y, 36,317-321$.

Channel R, Lomolino M (2000) Dynamic biogeography and conservation of endangered species. Nature, 403, 84-86.

Chown SL, Gaston KJ (2008) Macrophysiology for a changing world. Proceedings of the Royal Society B: Biological Sciences, 275, 1469-1478.

Chuine I, Beaubien E (2001) Phenology is a major determinant of temperate tree range. Ecology Letters, 4, 500-510.

Coops NC, Waring RH, Schroeder T (2009) Combining a generic process-based productivity model and a statistical classification method to predict the presence and absence of tree species in the Pacific Northwest, U.S.A. Ecological Modelling, 220, 1787-1796

Coudun C, Gegout JC, Piedallu C, Rameau JC (2006) Soil nutritional factors improve plant species distribution an illustration with Acer campestre (L.) in France. Journal of Biogeography, 33, 1750-1763.

Cowling RM, Rundel PW, Lamont BB, Kalin Arroyo M, Arianoutsou M (1996) Plant diversity in Mediterranean-climate regions. Trends in Ecology and Evolution, 11, 362-366.

Dai YJ, Dickenson RE, Wang YP (2004) A two-big-leaf model for canopy temperature, photosynthesis, and stomatal conductance. Journal of Climate, 17, 2281-2299.

Davis AJ, Jenkinson LS, Lawton JL, Shorrocks B, Wood S (1998) Making mistakes when predicting shifts in species range in response to global warming. Nature, 391, 783-786.

Davis MB, Shaw RG (2001) Range shifts and adaptive responses to quaternary climate change. Science, 292, 673-679.

de Graaff MA, van Groeninger KJ, Six J, Hungate BA, van Kessel C (2006) Interactions between plant growth and nutrient dynamics under elevated $\mathrm{CO}_{2}$ : a meta analysis. Global Change Biology, 12, 1-15.

Duquesnay A, Breda N, Stievenard M, Dupouey JL (1998) Changes of tree-ring $\mathrm{d}^{13} \mathrm{C}$ and water-use efficiency of beech (Fagus sylvatica L.) in north-eastern France during the past century. Plant, Cell and Environment, 21, 565-572.

Easterling W, Aggarwal PK, Batima P et al. (2007) Food, Fibre and Forest Products, pp. 273-313. Cambridge University Press, Cambridge, UK. 
Ehrlinger JR, Cerling TE (1995) Atmospheric $\mathrm{CO}_{2}$ and the ratio of intercellular to ambient $\mathrm{CO}_{2}$ levels in plants. Tree Physiology, 15, 105-111.

Elith J, Graham CH, Anderson RP et al. (2006) Novel methods improve prediction of species' distributions from occurrence data. Ecography, 29, 151.

Elser J, Bracken M, Cleland EE et al. (2007) Global analysis of nitrogen and phosphorus limitation of primary producers in freshwater, marine and terrestrial ecosystems. Ecology Letters, 10, 1135-1142.

Fahrig L (2003) Effects of habitat fragmentation on biodiversity. Annual Review of Ecology and Systematics, 34, 487-515.

Farquhar GD, von Caemmerer S, Berry JA (1980) A biochemical model of photosynthetic $\mathrm{CO}_{2}$ assimilation in leaves of $\mathrm{C}_{3}$ species. Planta, 149, 78-90.

Ferrier S (2002) Mapping spatial pattern in biodiversity for regional conservation planning: where to from here? Systems Biology, 51, 331-363.

Field R, O'Brian EM, Whittaker RJ (2005) Global models for predicting woody plant richness from climate: development and evaluation. Ecology, 86, 2263-2277.

Finzi AC, Norby RJ, Calfapietra C et al. (2007) Increases in nitrogen uptake rather than nitrogen-use efficiency support higher rates of temperate forest productivity under elevated $\mathrm{CO}_{2}$. Proceedings of the National Academy of Sciences of the United States of America, 104, 14014-14019.

Fitter AH, Fitter RSR (2002) Rapid changes in flowering time in British plants. Science, 296, 1689-1691.

Francey RJ, Farquhar GD (1982) An explanation of ${ }^{13} \mathrm{C} /{ }^{12} \mathrm{C}$ variations in tree rings. Nature, 297, 28-31.

Friedman J (1991) Multivariate adaptive regression splines. Annals of Statistics, 19, $1-1141$.

Funk V, Richardson K (2002) Systematic data in biodiversity studies: use it or lose it. Systems Biology, 51, 303-316.

Gaucharel C, Guiot J, Misson L (2008) Changes of the potential distribution area of French Mediterranean forests under global warming. Biogeosciences, 5, 1493-1503.

Gibelin AL, Deque M (2003) Anthropogenic climate change over the Mediterranean region simulated by a global variable resolution model. Climate Dynamics, 20, 327-339.

Giorgi F (2006) Climate change hot-spots. Geophysical Research Letters, 33, L08707, doi $10.1029 / 2006$ GL025734.

Giorgi F, Bi X, Pal J (2004) Mean, interannual variability and trends in a regional climate change experiment over Europe. II: climate change scenarios (2071-2100). Climate Dynamics, 23, 839-858.

Gomez-Mendoza L, Arriaga L (2007) Modeling the effect of climate change on the distribution of oak and pine species of Mexico. Conservation Biology, 21, 1545-1555.

Gordo O, Sanz JJ (2005) Phenology and climate change: a long-term study in a Mediterranean locality. Oecologia (Berlin), 146, 484-495.

Gracia CA, Tello E, Sabate S, Bellot J (1999) GOTILWA: an integrated model of water dynamics and forest growth. In: Ecology of Mediterranean Evergreen Oak Forests (eds Rodà F, Retana J, Gracia CA, Bellot J), pp. 163-179. Springer-Verlag, Berlin.

Guisan A, Thuiller W (2005) Predicting species distribution: offering more than simple habitat models. Ecology Letters, 8, 993-1009.

Gunderson CA, Sholtis JD, Wullschleger SD, Tissue DT, Hanson PJ, Norby RJ (2002) Environmental and stomatal control of photosynthetic enhancement in the canopy of a sweetgum (Liquidambar styraciflua L.) plantation during 3 years of $\mathrm{CO}_{2}$ enrichment. Plant, Cell and Environment, 25, 379-393.

Hampe A (2004) Bioclimate envelope models: what they detect and what they hide. Global Ecology and Biogeography, 13, 469-476.

Hastie TJ, Tibshirani R (1990) Generalized Additive Models. Chapman \& Hall, New York.

Hawkins BA, Field R, Cornell HV et al. (2003) Energy, water, and broad-scale geographic patterns of species richness. Ecology, 84, 3105-3117.

Heikkinen RK, Luoto M, Araújo MB, Virkkala R, Thuiller W, Sykes MT (2006) Methods and uncertainties in bioclimatic envelope modeling under climate change. Progress in Physical Geography, 30, 751-777.

Hickler T, Fronzek S, Araújo MB, Schweiger O, Thuiller W, Sykes MT (2009) An ecosystem model-based estimate of changes in water availability differs from water proxies that are commonly used in species distribution models. Global Ecology and Biogeography, 18, 304-313.

Hickler T, Smith B, Prentice IC, Mjofors K, Miller P, Arneth A, Sykes MT (2008) $\mathrm{CO}_{2}$ fertilization in temperate FACE experiments not representative of boreal and tropical forests. Global Change Biology, 14, 1531-1542.

Hijmans RJ, Cameron SE, Parra JL, Jones PG, Jarvis A (2005) Very high resolution interpolated climate surfaces for global land areas. International Journal of Climatology, 25, 1965-1978.

Hijmans RJ, Graham CH (2006) The ability of climate envelope models to predict the effect of climate change on species distributions. Global Change Biology, 12, 2272-2281.
Hungate B, Dukes JS, Shaw MR, Luo Y, Field CB (2003) Nitrogen and climate change. Science, 302, 1512-1513.

IPCC WGI (2007) Climate Change 2007: climate change impacts, adaptation and vulnerability. In: Contribution of Working Group I to the Fourth Assessment Report of the Intergovernmental Panel on Climate Change, 2007 (eds Parry ML, Canziani OF, Palutikof JP, van der Linden PJ, Hanson CE). Cambridge University Press, Cambridge, UK.

Iverson LR, Prasad AM (2001) Potential changes in tree species richness and forest community types following climate change. Ecosystems, 4, 186-199.

Jain A, Yang X, Kheshgi H, McGuire AD, Post W, Kicklighter D (2009) Nitrogen attenuation of terrestrial carbon cycle response to global environmental factors. Global Biogeochemical Cycles, 23, GB4028, doi: 10.1029/2009GB003519.

Jeltsch F, Moloney KA, Schurr FM, Kochy M, Schwager M (2008) The state of plant population modelling in light of environmental change. Perspectives in Plant Ecology, Evolution and Systematics, 9, 171-190.

Jung M, le Maire G, Zaehle S et al. (2007) Assessing the ability of three land ecosystem models to simulate gross carbon uptake of forests from boreal to Mediterranean climate in Europe. Biogeosciences, 4, 647-656.

Kearney M (2006) Habitat, environment and niche: what are we modelling? Oikos, 115, 186-191.

Keenan T, Garcia R, Friend AD, Zaehle S, Gracia C, Sabate S (2009a) Improved understanding of drought controls on seasonal variation in Mediterranean forest canopy $\mathrm{CO}_{2}$ and water fluxes through combined in situ measurements and ecosystem modelling. Biogeosciences, 6, 1423-1444

Keenan T, Niinemets Ü, Sabate S, Gracia C, Peñuelas J (2009b) Process based inventory of isoprenoid emissions: current knowledge, future prospects and uncertainties. Atmospheric Chemistry and Physics, 9, 4053-4076.

Keenan T, Niinemets Ü, Sabate S, Gracia C, Peñuelas J (2009c) Seasonality of monoterpene emission potentials in Quercus ilex and Pinus pinea: implications for regional VOC emissions modeling. Journal of Geophysical Research, 114, D22202, doi: 10.1029/2009JD011904.

Keenan T, Sabate S, Gracia C (2010) Soil water stress and coupled photosynthesisconductance models: bridging the gap between conflicting reports on the relative roles of stomatal, mesophyll conductance and biochemical limitations to photosynthesis. Agricultural and Forest Meteorology, 150, 443-453.

Keenan T, Sabate S, Gracia CA (2008) Forest eco-physiological models and carbon sequestration. In: Managing Forest Ecosystems: The Challenge of Climate Change (eds Bravo F, LeMay V, Jandl R, von Gadow K), pp. 83-102. Springer, Berlin.

Keith DA, Akcakaya HR, Thuiller W et al. (2008) Predicting extinction risks under climate change: coupling stochastic population models with dynamic bioclimatic habitat models. Biology Letters, 4, 560-563.

Kharouba H, Algar A, Kerr J (2009) Historically calibrated predictions of butterfly species' range shift using global change as a pseudo-experiment. Ecology, 90, 2213-2222.

Körner C (2006) Plant $\mathrm{CO}_{2}$ responses: an issue of definition, time and resource supply New Phytologist, 172, 393-411.

Kramer K, Leinonen I, Bartelink HH et al. (2002) Evaluation of six process-based forest growth models using eddy-covariance measurements of $\mathrm{CO}_{2}$ and $\mathrm{H}_{2} \mathrm{O}$ fluxes at six forest sites in Europe. Global Change Biology, 8, 213-230.

Leakey ADB, Ainsworth EA, Bernacchi CJ, Rogers A, Long SP, Ort DR (2009) Elevated $\mathrm{CO}_{2}$ effects on plant carbon, nitrogen, and water relations: six important lessons from FACE. Journal of Experimental Botany, 60, 2859-2876.

LeBauer DS, Treseder KK (2008) Nitrogen limitation of net primary productivity in terrestrial ecosystems is globally distributed. Ecology, 89, 371-379.

Leuning R, Kelliher FM, De Pury DGG, Schulze E-D (1995) Leaf nitrogen, photosynthesis, conductance and transpiration: scaling from leaves to canopies. Plant, Cell and Environment, 18, 1183-1200.

Lischke H, Zimmermann NE, Bolliger J, Rickebusch S, Löffler TJ (2006) TreeMig: a forest-landscape model for simulating spatio-temporal patterns from stand to landscape scale. Ecological Modelling, 199, 409-420.

Long SP, Ainsworth EA, Leakey ADB, Nösberger J, Ort DR (2006) Food for thought: lower-than-expected crop yield stimulation with rising $\mathrm{CO}_{2}$ concentrations. Science, 312, 1918-1921.

Luo Y, Hui D, Zhang D (2006) Elevated $\mathrm{CO}_{2}$ stimulates net accumulations of carbon and nitrogen in land ecosystems: a meta-analysis. Ecology, 87, 53-63.

Luo Y, Su B, Currie WS et al. (2004) Progressive nitrogen limitation of ecosystem responses to rising atmospheric carbon dioxide. BioScience, 54, 731-739.

McCullagh P, Nelder JA (1989) Generalized Linear Models. Chapman \& Hall, New York.

McGuire AD, Sitch S, Clein JS et al. (2001) Carbon balance of the terrestrial biosphere in the twentieth century: analyses of $\mathrm{CO}_{2}$, climate and land use effects with four process-based ecosystem models. Global Biogeochemical Cycles, 15, 183-206. 
Medlyn BE, Jarvis PG (1999) Design and use of a database of model parameters from elevated $\left[\mathrm{CO}_{2}\right]$ experiments. Ecological Modelling, 124, 69-83.

Ministerio de Agricultura PyA (2007) Tercero Inventario Forestal Nacional. Ministerio de Agricultura PyA, Madrid, Spain.

Montoya D, Purves DW, Urbietal IR, Zavala MA (2009) Do species distribution models explain spatial structure within tree species ranges. Global Ecology and Biogeography 18, 662-673.

Morales P, Sykes MT, Prentice IC et al. (2005) Comparing and evaluating process-based ecosystem model predictions of carbon and water fluxes in major European fores biomes. Global Change Biology, 11, 1-23.

Morin X, Augspurger C, Chuine I (2007) Process-based modeling of tree species' distributions: what limits temperate tree species' range boundaries? Ecology, 88, 2280-2291.

Morin X, Thuiller W (2009) Comparing niche- and process-based models to reduce prediction uncertainty in species range shifts under climate change. Ecology, 90, 1301-1313.

Morison JIL (1998) Stomatal response to increased $\mathrm{CO}_{2}$ concentration. Journal of Experimental Botany, 49, 443-452.

New M, Hulme M, Jones PD (1999) Representing twentieth century space-time climate variability. Part 1: development of a 1961-1990 mean monthly terrestrial climatology. Journal of Climate, 12, 829-856.

Nigh GD, Ying CC, Qian H (2004) Climate and productivity of major conifer species in the interior of British Columbia Canada. Forest Science, 50, 659-671.

Ninyerola M, Pons X, Roure JM (2007a) Objective air temperature mapping for the Iberian Peninsula using spatial interpolation and GIS. International Journal of Climatology, 27, 1231-1242.

Ninyerola M, Pons X, Roure JM (2007b) Monthly precipitation mapping of the Iberian Peninsula using spatial interpolation tools implemented in a Geographic Information System. Theoretical and Applied Climatology, 89, 195-209.

Nogues-Bravo D (2009) Predicting the past distribution of species climatic niches. Global Ecology and Biogeography, 18, 521-531.

Norby RJ, Luo Y (2004) Evaluating ecosystem responses to rising atmospheric $\mathrm{CO}_{2}$ and global warming in a multi-factor world. New Phytologist, 162, 281-293.

Pacala SW (1997) Dynamics of plant communities. In: Plant Ecology (ed. Crawley MJ), pp. 532-555. Blackwell Scientific Publications, Oxford.

Pacala SW, Canham CD, Silander JA Jr (1993) Forest models defined by field measurements: 1 . The design of a northeastern forest simulator. Canadian Journal of Forest Research, 23, 1980-1988.

Parra JL, Monahan WB (2008) Variability in 20th century climate change reconstructions and its consequences for predicting geographic responses of California mammals. Global Change Biology, 14, 2215-2231.

Parry ML, Rosenzweig C, Iglesias A, Livermore M, Fischer G (2004) Effects of climate change on global food production under SRES emissions and socio-economic scenarios. Global Environmental Change-Human and Policy Dimensions, 14, 53-67.

Pearman PB, Guisan A, Breonnimann O, Randin CF (2008) Niche dynamics in space and time. Trends in Ecology and Evolution, 23, 149-158.

Pearson RG, Thuiller W, Araújo MB et al. (2006) Model-based uncertainty in species range prediction. Journal of Biogeography, 33, 1704-1711.

Pelkonen P, Hari P (1980) The dependence of the springtime recovery of $\mathrm{CO}_{2}$ uptake in Scots pine on temperature and internal factors. Flora, 169, 398-404.

Peñuelas J, Azcón-Bieto J (1992) Changes in leaf $\Delta^{13} \mathrm{C}$ of herbarium plant species during the last 3 centuries of $\mathrm{CO}_{2}$ increase. Plant, Cell and Environment, 5, 485-489.

Peñuelas J, Filella I (2001) Phenology - responses to a warming world. Science, 294 793-795.

Peñuelas J, Hunt JM, Ogaya R, Jump AS (2008) Twentieth century changes of tree-ring delta ${ }^{13} \mathrm{C}$ at the southern range-edge of Fagus sylvatica: increasing water-use efficiency does not avoid the growth decline induced by warming at low altitudes. Global Change Biology, 14, 1076-1088.

Peterson AT (2007) Uses and requirements of ecological niche models and related distributional models. Biodiversity Informatics, 3, 59-72.

Picon C, Guehl JM, Aussenac G (1996) Growth dynamics, transpiration and water-use efficiency in Quercus robur plants submitted to elevated $\mathrm{CO}_{2}$ and drought. Annals of Forest Science, 53, 431-446.

Randin CF, Dirnböck T, Dullinger S, Zimmermann NE, Zappa M, Guisan A (2006) Are niche-based species distribution models transferable in space? Journal of Biogeography, 33, 1689-1703.

Reich PB, Hobbie SE, Lee Tet al. (2006) Nitrogen limitation constrains sustainability of ecosystem response to $\mathrm{CO}_{2}$. Nature, 440, 922-925.

Richardson AD, Williams M, Hollinger D et al. (2010) Estimating parameters of a forest ecosystem $\mathrm{C}$ model with measurements of stocks and fluxes as joint constraints. Oecologia (Berlin), doi: 10.1007/s00442-010-1628-y.
Rickebusch S, Thuiller W, Hickler T, Araújo MB, Sykes MT, Schweiger O, Lafourcade B (2008) Incorporating the effects of changes in vegetation functioning and $\mathrm{CO}_{2}$ on water availability in plant habitat models. Biology Letters, 4, 556-559.

Ricklefs R (2004) A comprehensive framework for global patterns in biodiversity. Ecological Letters, 7, 1-15.

Ridgeway G (1999) The state of boosting. Computational and Scientific Statistics, 31, 172-181.

Ripley BD (1996) Pattern Recognition and Neural Networks. Cambridge University Press, Cambridge, UK.

Rodà F, Avila A, Rodrigo A (2002) Nitrogen deposition in Mediterranean forests. Environmental Pollution, 118, 205-213.

Rushton SP, Ormerod SJ, Kerby G (2004) New paradigms for modelling species distributions? Journal of Applied Ecology, 41, 193-200.

Scheller RM, Mladenoff DJ (2007) An ecological classification of forest landscape simulation models: tools and strategies for understanding broad-scale forested ecosystems. Landscape Ecology, 22, 491-505.

Schröter D, Cramer W, Leemans R et al. (2005) Ecosystem service supply and vulnerability to global change in Europe. Science, 25/310, 1333-1337.

Sitch S, Huntingford C, Gedney N et al. (2008) Evaluation of the terrestrial carbon cycle, future plant geography and climate-carbon cycle feedbacks using five Dynamic Global Vegetation Models (DGVMs). Global Change Biology, 14, 2015-2039.

Skov F, Svenning JC (2004) Potential impact of climatic change on the distribution of forest herbs in Europe. Ecography, 27, 366-380.

St Clair JB, Howe GT (2007) Genetic maladaptation of coastal Douglas-fir seedlings to future climates. Global Change Biology, 13, 1441-1454.

Svenning JC, Normand S, Skov F (2008) Postglacial dispersal limitation of widespread forest plant species in nemoral Europe. Ecography, 31, 316-326.

Svenning JC, Skov F (2004) Limited filling of the potential range in European tree species. Ecology Letters, 7, 565-573.

Swets JA (1988) Measuring the accuracy of diagnostic systems. Science, 240, 1285-1293.

Thomas CD, Bodsworth EJ, Wilson RJ, Simmons AD, Davies ZG, Musche M, Conrad L (2001) Ecological and evolutionary processes at expanding range margins. Nature, 411, 577-581.

Thomas CD, Cameron A, Green RE et al. (2004) Extinction risk from climate change. Nature, 427, 145-148.

Thornton PE, Lamarque J-F, Rosenbloom NA, Mahowald NM (2007) Influence of carbon-nitrogen cycle coupling on land model response to $\mathrm{CO}_{2}$ fertilization and climate variability. Global Biogeochemical Cycles, 21, doi: 10.1029/2006GB002868.

Thuiller W (2003) BIOMOD - optimizing predictions of species distributions and projecting potential future shifts under global change. Global Change Biology, 9, 1353-1362.

Thuiller W (2007) Biodiversity-climate change and the ecologist. Nature, 448, 550-552.

Thuiller W (2010) Patterns and uncertainties of species' range shifts under climate change. Global Change Biology, 10, 2020-2027.

Thuiller W, Albert $\mathrm{CH}$, Araujo $\mathrm{M}$ et al. (2008) Predicting global change impacts on plant species distributions: future challenges. Perspectives in Plant Ecology, Evolution and Systematics, 9, 137-152.

Thuiller W, Araujo MB, Lavorel S (2003) Generalized models vs. classification tree analysis: predicting spatial distributions of plant species at different scales. Journal of Vegetation Science, 14, 669-680.

Thuiller W, Lafourcade B, Engler R, Araújo MB (2009) BIOMOD - a platform for ensemble forecasting of species distributions. Ecography, 32, 369-373.

Thuiller W, Lavorel S, Araujo MB, Sykes MT, Prentice C (2005) Climate change threats to plant diversity in Europe. Proceedings of the National Academy of Sciences, 102, $8245-8250$

Thuiller W, Lavorel S, Sykes MT, Araújo MB (2006a) Using niche-based modelling to assess the impact of climate change on tree functional diversity in Europe. Diversity and Distributions, 12, 49-60.

Thuiller W, Midgley GF, Hughes GO, Bomhard B, Drew G, Rutherford MC, Woodward FI (2006b) Endemic species and ecosystem vulnerability to climate change in Namibia. Global Change Biology, 12, 759-776.

Tubiello FN, Soussana JF, Howden SM (2007) Crop and pasture response to climate change. Proceedings of the National Academy of Sciences, 104, 19686-19690.

Underwood EC, Viers JH, Klausmeyer KR, Cox RL, Shaw MR (2009) Threats and biodiversity in the Mediterranean biome. Diversity and Distributions, 15, 188-197.

van der Meer PJ, Jorritsma ITM, Kramer JK (2002) Assessing climate change effects on long-term forest development: adjusting growth, phenology and seed production in a gap model. Forest Ecology and Management, 162, 39-52.

Volis S, Mendlinger S, Turuspekov Y, Esnazarov U (2002) Phenotypic and allozyme variation in Mediterranean and desert populations of wild barley, Hordeum spontaneum. Evolution, 56, 1403-1415. 
Wang Y-P, Leuning R (1998) A two-leaf model for canopy conductance, photosynthesis and partitioning of available energy I: model description and comparison with a multi-layered model. Agricultural and Forest Meteorology, 91, 89-111.

Waterhouse JS, Switsura VR, Barkera AC, Cartera AHC, Hemming DL, Loaderd NJ, Robertsond I (2004) Northern European trees show a progressively diminishing response to increasing atmospheric carbon dioxide concentrations. Quaternary Science Reviews, 23, 803-810.

Zaehle S, Friedlingstein P, Friend AD (2010) Terrestrial nitrogen feedbacks may accelerate future climate change. Geophysical Research Letters, 37, L01401, doi 10.1029/2009GL041345.
Zaehle S, Friend A (2010) Carbon and nitrogen cycle dynamics in the O-CN land surface model, I: model description, site-scale evaluation and sensitivity to parameter estimates. Global Biogeochemical Cycles, doi: 10.1029/2009GB003521.

Zavala JA, Casteel CL, DeLucia EH, Berenbaum MR (2008) Anthropogenic increase in carbon dioxide compromises plant defense against invasive insects. Proceedings of the National Academy of Sciences, 105, 5129-5133.

Zierl B, Bugmann H (2007) Sensitivity of carbon cycling in the European Alps to changes of climate and land cover. Climatic Change, 85, 195-212. 